\title{
Incidence, Prevalence, and Clinical Epidemiology of Inflammatory Bowel Disease in the Arab World: A Systematic Review and Meta-Analysis
}

\author{
Mahmoud Moslic Sameer Alawadhi ${ }^{\mathrm{a}} \quad$ Fuad Hasan $^{\mathrm{b}}$ Antoine Abou Rached ${ }^{\mathrm{d}}$ \\ Faisal Sanai ${ }^{e}$ Silvio Danese ${ }^{f}$

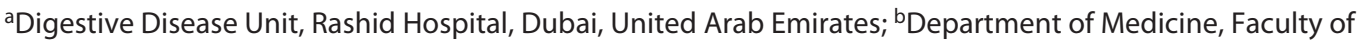 \\ Medicine, Kuwait University, Kuwait City, Kuwait; ' $\mathrm{C}$ astroenterologist and Inflammatory Bowel Disease Specialist, \\ King Abdulaziz University Hospital, Jeddah, Saudi Arabia; ${ }^{d}$ School of Medicine, Lebanese University, Hadath,

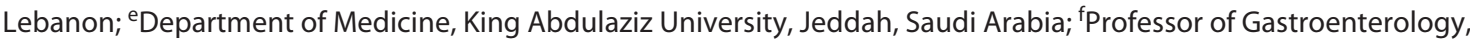 \\ Faculty of Medicine, Humanitas University, Milan, Italy
}

\section{Keywords}

Inflammatory bowel disease · Epidemiology · Incidence ·

Arab world

\begin{abstract}
Objectives: Despite the recent findings of the rising incidence of inflammatory bowel disease (IBD) in Arab countries, there are limited data on the characteristics of IBD patients and the disease course in the Arab world. This systematic review aimed to investigate the incidence and epidemiology of IBD in the Arab world. Material and Methods: We conducted a systematic literature review that utilized a comprehensive search of PubMed, Cochrane Central, SCOPUS, Google Scholar, and Web of Science from their inception till August 2020. We included cross-sectional, prospective, and retrospective studies that examined the prevalence and/or epidemiological characteristics of IBD in Arab countries. $\boldsymbol{R} \boldsymbol{e}$ sults: A total of 16 studies that examined IBD in Saudi Arabia, Egypt, Kuwait, the United Arab Emirates, Bahrain, Lebanon, and Oman were included. Generally, the included studies covered the period from the early 1990s to the late 2010s. A total of 1,627 ulcerative colitis (UC) patients and 1,588 Crohn's disease (CD) patients were included in this system-
\end{abstract}

karger@karger.com www.karger.com/iid

Karger!"
(C) 2021 The Author(s)

Published by S. Karger AG, Basel

This is an Open Access article licensed under the Creative Common Attribution-NonCommercial-4.0 International License (CC BY-NC) (http://www.karger.com/Services/OpenAccessLicense), applicable to the online version of the article only. Usage and distribution for commercial purposes requires written permission. atic review. The mean age at diagnosis ranged from 24.13 to 43.6 years in adult cases and from 4.5 to 16 years in pediatric cases. In most of the included studies, the majority of patients were male. The quantitative analysis revealed a pooled incidence rate of 2.33 (95\% confidence interval [CI] 1.2-3.4) per 100,000 persons per year for UC in the Arab world. Likewise, the pooled incidence rate for CD in the Arab world was 1.46 (95\% Cl 1.03-1.89) per 100,000 persons per year. Conclusion: There is a growing incidence of IBD in the Arab world, while IBD patients from Arab countries may present with some different characteristics, compared to their counterparts in Europe.

(C) 2021 The Author(s).

Published by S. Karger AG, Basel

\section{Introduction}

Crohn's disease (CD) and ulcerative colitis (UC) are chronic inflammatory diseases affecting the gastrointestinal tract and are collectively known as inflammatory bowel diseases (IBDs) [1-3]. UC generally affects the large intestine and rectum, whereas CD can target any part of the gut [3]. Historical data have shown that the younger demographic is more susceptible to IBD, causing 
a significant alteration in their quality of life, alongside debilitating morbidity and exacerbations $[1,3]$. The etiology of IBD is not well-established; however, contemporary hypotheses implicate an interaction of environmental and immunoregulatory factors in genetically vulnerable individuals [1-4].

Western countries have been historically observed as the populations where IBD is prevalent and continues to rise, whereas the general impression is that countries in the Middle East (ME) experience a lower incidence of IBD $[1,5]$. Incidence rates vary considerably depending on the region. In 2017, UC incidence rates ranged from 0.97 to 57.9 per 100,000 in Europe, 8.8 to 23.14 per 100,000 in North America, and 0.15 to 6.5 per 100,000 in Asia and the ME [5]. Nonetheless, recent trends have shown a significant rise in the incidence of IBD in ME countries, which were linked to "westernization" in lifestyle, including dietary habits in these countries [1, 2, 5-7].

Despite the recent findings of the rising incidence of IBD in Arab countries, there are limited data on the characteristics of IBD patients and the disease course in the Arab world. This systematic review aimed to investigate the incidence and epidemiology of IBD in the Arab world.

\section{Methods}

This present study was conducted following the recommendations provided by the meta-analysis of observational studies in epidemiology (MOOSE) statement [8] and in strict accordance with the Cochrane Handbook of Systematic Reviews [9].

\section{Literature Search Strategy}

We conducted a systematic literature review that utilized a comprehensive search of PubMed, Cochrane Central, SCOPUS, Google Scholar, and Web of Science from their inception till August 2020 using the following query: \{(inflammatory bowel diseases [MeSH Terms]) OR (Crohn's disease [MeSH Terms]) OR (ulcerative colitis [MeSH Terms])\} AND ("Egypt" OR "Saudi Arabia" OR "United Arab Emirates" OR "Oman" OR "Qatar" OR "Bahrain" OR "Kuwait” OR "Syria” OR "Libya” OR "Iraq" OR “Tunisia” OR “Algeria” OR "Morocco" OR "Palestine” OR "Yemen" OR "Lebanon"). We also searched the bibliography of eligible studies to find relevant articles.

\section{Eligibility Criteria and Study Selection}

We included cross-sectional, prospective, and retrospective studies that examined the prevalence and/or epidemiological characteristics of IBD in one of the following Arab countries: Egypt, KSA, UAE, Oman, Qatar, Bahrain, Kuwait, Syria, Libya, Iraq, Tunisia, Algeria, Morocco, Palestine, Yemen, and Lebanon. We excluded: (a) Studies that included patients with any other inflammatory or autoimmune diseases rather than IBD without separate analysis; (b) studies that included patients with any nationally other than the above-listed countries; (c) studies that were performed on animal models; (d) review articles; and (e) non-English articles and duplicate references.

Eligibility screening was conducted in 2 steps, each by 2 independent reviewers: (a) title and abstract screening for matching the inclusion criteria and (b) full-text screening for the complete fulfillment of the eligibility criteria. Disagreements were resolved upon the opinion of a third reviewer.

\section{Data Extraction}

Two independent authors extracted the data and another reviewer resolved disagreements. The extracted data included the following: (a) baseline characteristics of enrolled patients; (b) general characteristics of study design; (c) type of the patients; (d) incidence and prevalence of IBD; (e) epidemiological characteristics of the affected patients; and (f) summary of the main finding.

\section{Quantitative Analysis}

The incidence of IBD was pooled using a Freeman-Tukey transformation. Heterogeneity was assessed by visual inspection of the forest plots and measured by $I^{2}$ and $\chi^{2}$ tests. The $\chi^{2}$ test measures the existence of significant heterogeneity, while the $I^{2}$ quantifies the magnitude of heterogeneity in the effect size. We assessed and interpreted heterogeneity according to the recommendations in the "Cochrane Handbook of Systematic Reviews and MetaAnalysis" (chapter 9). In this handbook, an alpha level (for $\chi^{2}$ test) below 0.1 is considered to be significant heterogeneity, and the $I^{2}$ test was interpreted as follows: (0-40\%: might not be important; 30-60\%: may represent moderate heterogeneity; 50-90\%: may represent substantial heterogeneity). We performed a sensitivity analysis to ensure that none of the included studies affected the results and to examine whether the overall effect size is statistically robust. We excluded 1 study in each scenario. We used OpenMeta (Analyst) for Windows.

\section{Results}

\section{Selection of Studies}

A total of 1,899 unique citations were retrieved from online bibliographic search and manual retrieval of references. Of them, 147 full texts were retained for a full evaluation, and 16 studies (total no. of IBD patients $=3,221$ ) were finally included in the present systematic review and meta-analysis (Fig. 1).

\section{Summary Characteristics of the Included Studies}

A total of 2 case series [1, 10], 1 cross-sectional [11], 1 prospective study [12], and 12 retrospective studies [6, 13-24] were included in the present systematic review. Eight articles examined IBD in Saudi Arabia $[6,10,14$, 16-20], while the rest of the studied included patients from Egypt [1], Kuwait [11, 13, 24], the UAE [15], Bahrain [21], Lebanon [22], and Oman [12]. Generally, the included studies covered the period from the early $1990 \mathrm{~s}$ to the late 2010s (Table 1). 


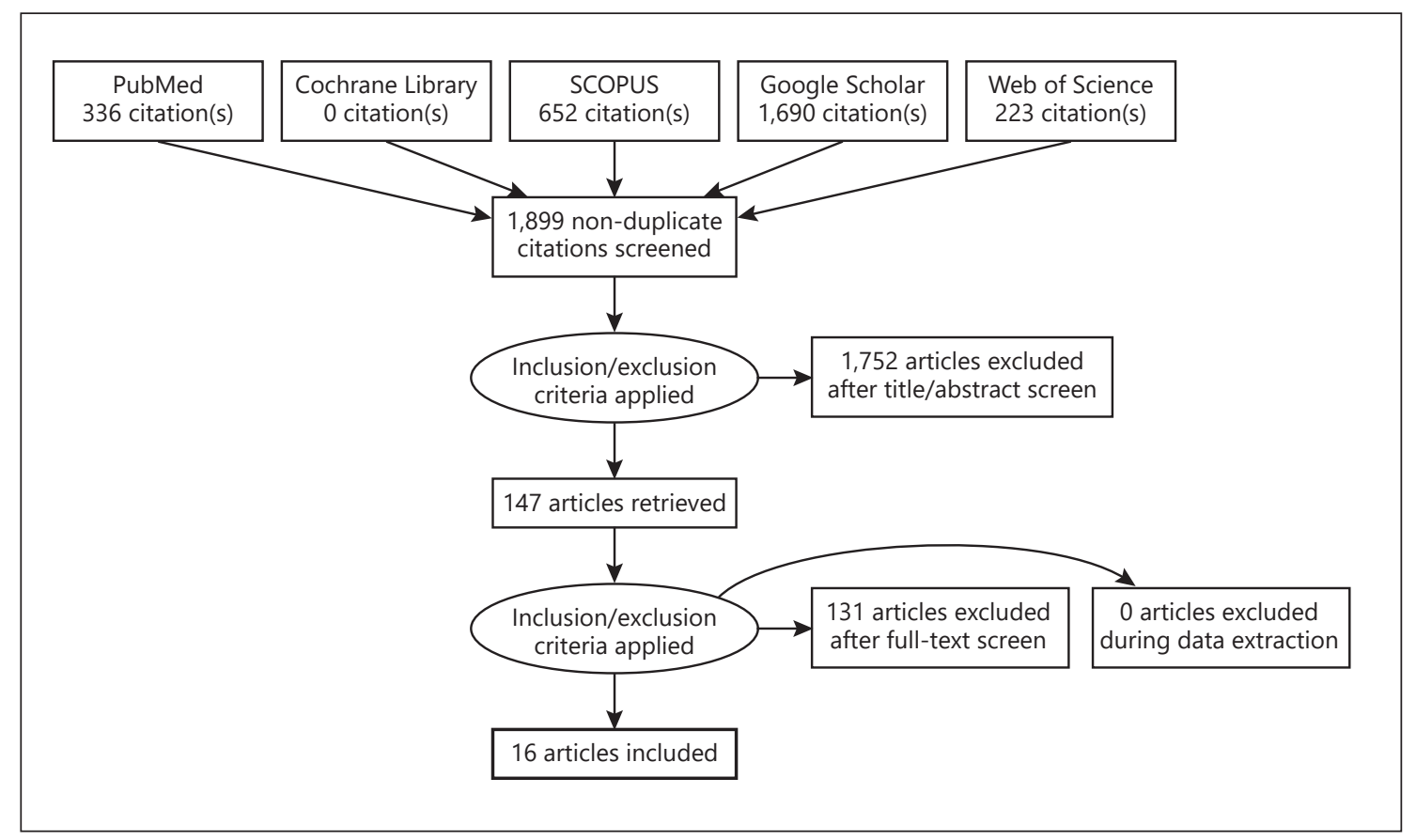

Fig. 1. PRISMA flowchart of the included studies.

\section{Incidence and Prevalence of IBD}

Six included studies reported the incidence and/or prevalence of IBD in the aforementioned countries. In the study reported by Al-Shamali et al. [13], a retrospective review of all patients presented with a confirmed diagnosis of UC in Kuwait City, a total of 346 patients were identified. The authors reported that the local incidence of UC was 2.8 per 100,000 persons per year. Another study from Kuwait reported that the incidence of pediatric IBD was 2.6 per 100,000 persons per year [24]. Al-Ghamdi et al. [19] retrieved the data of all confirmed cases with CD in a tertiary center in Riyadh, KSA, and estimated that the incidence of CD increased from 0.32 per 100,000 persons per year between 1983 and 1993 to 1.66 per 100,000 persons per year between 1994 and 2004 with a combined mean annual incidence of 0.94 per 100,000 persons per year over these 20 years. In another retrospective study from Bahrain, it was found that the average number of CD cases increased from 0.4 between the years 1984 and 2001 to 4 cases per year between 2002 and 2014. For UC, the average number of cases between 1984 and 2001 was 2 , while this increased to 8 for the years 2002-2014. Overall, the prevalence of IBD was found to be 26.25 per 100,000 persons [21]. In the prospective study of IBD patients in Oman, it was reported that the incidence of UC was 1.35 per 100,000 persons per year [12]. Abdul-Baki et al. [22] collected data of IBD patients in Beirut and reported a mean annual incidence of 4.1 per 100,000 people for UC, 1.4 per 100,000 people for CD, and a total annual incidence of IBD of 5.5 per 100,000 people per year (Table 2; Fig. 2).

\section{Quantitative Analysis}

The quantitative analysis revealed that the incidence of UC in the Arab world was 2.33 (95\% confidence interval 1.2-3.4; Fig. 3a) per 100,000 persons per year, the pooled estimate showed significant heterogeneity $\left(p<0.001 ; I^{2}=\right.$ $83 \%)$. Likewise, the quantitative analysis revealed that the incidence of CD in the Arab world was 1.46 (95\% confidence interval 1.03-1.89; Fig. 3b) per 100,000 persons per year, the pooled estimate showed no significant heterogeneity $\left(p=0.91 ; I^{2}=0 \%\right)$.

Clinical Characteristics and Diagnosis of IBD Patients

A total of 1,627 UC patients and 1,588 CD patients were included in this systematic review. The full disease characteristics are presented in Tables 3 and 4 . The mean age at diagnosis ranged from 24.13 to 43.6 years in adult cases and from 4.5 to 16 years in pediatric cases. In most of the included studies, the majority of patients were males (average $41-59 \%$ ). The majority of patients in the included studies had no previous history of smoking. 
Table 1. Summary characteristics of the included studies

\begin{tabular}{|c|c|c|c|c|c|c|c|c|}
\hline First author & $\begin{array}{l}\text { Year of } \\
\text { publication }\end{array}$ & $\begin{array}{l}\text { Study } \\
\text { period }\end{array}$ & Country & City & Study design & Population & \multicolumn{2}{|c|}{ Total casesIBD cases, $n$} \\
\hline Hossain et al. [10] & 1991 & NR & Saudi Arabia & Riyadh & Case series & Adults with CD & 7 & 7 \\
\hline $\begin{array}{l}\text { Al-Shamali et al. } \\
\text { [13] }\end{array}$ & 2003 & 14 years & Kuwait & Kuwait City & $\begin{array}{l}\text { Retrospective case } \\
\text { studies }\end{array}$ & & 346 & 90 \\
\hline Khan et al. [17] & 1996 & 5 years & Saudi Arabia & Al-Madinah & $\begin{array}{l}\text { Retrospective case } \\
\text { studies }\end{array}$ & $\begin{array}{l}\text { Al-Madinah patients who } \\
\text { underwent lower } \\
\text { gastrointestinal endoscopies }\end{array}$ & 1,182 & 111 \\
\hline Esmat et al. [1] & 2014 & 15 years & Egypt & Cairo & Case series & $\begin{array}{l}\text { Patients who presented for } \\
\text { gastrointestinal consultations } \\
\text { or interventions }\end{array}$ & 24,156 & $\begin{array}{l}157 \text { (135 with } \\
\text { UC/22 with IBD) }\end{array}$ \\
\hline Alharbi et al. [18] & 2014 & 4 years & Saudi Arabia & Riyadh & $\begin{array}{l}\text { Retrospective case } \\
\text { studies }\end{array}$ & $\begin{array}{l}\text { UC patients attending } 4 \text { gastroe } \\
\text { centers }\end{array}$ & enterology & 394 \\
\hline Aljebreen et al. [6] & 2013 & 3.5 years & Saudi Arabia & Riyadh & $\begin{array}{l}\text { Retrospective data- } \\
\text { registry based study }\end{array}$ & $\begin{array}{l}\text { CD patients in } 4 \text { tertiary care } \\
\text { gastroenterology centers }\end{array}$ & & 497 \\
\hline $\begin{array}{l}\text { Al-Ghamdi et al. } \\
\text { [19] }\end{array}$ & 2004 & 20 years & Saudi Arabia & Riyadh & Retrospective study & $\begin{array}{l}\text { All patients attending a gastroen } \\
\text { unit with a diagnosis of CD. }\end{array}$ & nterology & 77 \\
\hline $\begin{array}{l}\text { Al Fadda et al. } \\
{[2,20]}\end{array}$ & 2012 & 39 years & Saudi Arabia & Riyadh & Retrospective & $\begin{array}{l}\text { All cases of IBD from a tertiary } \\
\text { hospital }\end{array}$ & care & 312 \\
\hline Abdulla et al. [21] & 2017 & 30 years & Bahrain & Manama & Retrospective & $\begin{array}{l}\text { Patients between } 4 \text { and } 79 \text { years, } \\
\text { been diagnosed with UC, CD, or }\end{array}$ & $\begin{array}{l}\text { s, who had } \\
\text { or IC }\end{array}$ & 187 \\
\hline $\begin{array}{l}\text { Abdul-Baki et al. } \\
{[22]}\end{array}$ & 2007 & 4 years & Lebanon & Beirut & Retrospective & IBD patients in Beirut & 15,073 & 24 \\
\hline $\begin{array}{l}\text { El Mouzan et al. } \\
{[14]}\end{array}$ & 2012 & 17 years & Saudi Arabia & Riyadh & Retrospective study & $\begin{array}{l}\text { Children below } 18 \text { years present } \\
\text { pediatric gastroenterology cente }\end{array}$ & $\begin{array}{l}\text { ting at } 2 \\
\text { ers }\end{array}$ & $\begin{array}{l}218 \text { (71 with } \\
\text { UC/147 with CD) }\end{array}$ \\
\hline $\begin{array}{l}\text { Al Awar et al. } \\
{[15]}\end{array}$ & 2004 & 8 years & The UAE & Dubai & Retrospective study & Pediatric cases with IBD in Dub & & $\begin{array}{l}12 \text { (8 with } \mathrm{UC} / 3 \\
\text { with } \mathrm{CD} / 1 \text { with } \mathrm{IC})\end{array}$ \\
\hline
\end{tabular}

IBD, inflammatory bowel disease; CD, Crohn's disease; UC, ulcerative colitis; IC, indeterminate colitis; UAE, United Arab Emirates.

While the prevalence of family history ranged from 1.5 to $26.1 \%$. Only 1 study from Saudi Arabia reported the consanguinity rate, which was $32.6 \%$. Studies reported that hematochezia, diarrhea, urgency, and tenesmus were the main presenting features of the patients. Concerning the time to diagnosis, studies in Saudi population reported that the average time to diagnosis was nearly 6 months in $>90 \%$ of the patients with UC; while the study from Oman demonstrated that the average time to diagnosis was 13.2 months. The most common site of colon involvement 
Table 2. Incidence and prevalence of IBD in the Arab world

\begin{tabular}{|c|c|c|c|c|c|c|c|}
\hline \multirow[t]{2}{*}{ Study } & \multirow[t]{2}{*}{$\begin{array}{l}\text { Year of } \\
\text { publication }\end{array}$} & \multirow[t]{2}{*}{ Country } & \multirow[t]{2}{*}{ City } & \multicolumn{2}{|c|}{$\begin{array}{l}\text { Patients with } \\
\text { IBD, } n\end{array}$} & \multirow[t]{2}{*}{ Incidence } & \multirow[t]{2}{*}{ Prevalence } \\
\hline & & & & $\mathrm{UC}$ & $\mathrm{CD}$ & & \\
\hline Al-Shamali et al. [13] & 2003 & Kuwait & Kuwait City & 90 & & 2.85 & 41.73 \\
\hline Al-Ghamdi et al. [19] & 2004 & Saudi Arabia & Riyadh & & 77 & 0.94 & NR \\
\hline Abdulla et al. [21] & 2017 & Bahrain & Manama & 123 & 61 & NR & $\begin{array}{l}\text { IBD: } 26.25 / C D: 8.56 / \\
\text { UC: } 17.27 / \text { IC: } 0.42\end{array}$ \\
\hline Abdul-Baki et al. [22] & 2007 & Lebanon & Beirut & 16 & 8 & CD: $1.4 / \mathrm{UC}: 4.1$ & CD: 53.1/UC: 106.2 \\
\hline Radhakrishnan et al. [12] & 1997 & Oman & Muscat & 108 & 22 & UC: 1.35 & NR \\
\hline Al-Qabandi et al. [24] & 2011 & Kuwait & Kuwait city & 36 & 92 & $\begin{array}{l}\text { IBD: } 2.16 / C D: 1.53 / \\
\text { UC: } 0.6 / \text { IC: } 0.03\end{array}$ & \\
\hline
\end{tabular}

IBD, inflammatory bowel disease; CD, Crohn's disease; UC, ulcerative colitis; IC, indeterminate colitis; NR, not reported.

among the included studies was the left colon. Concerning disease severity and extent, ulcerative proctitis accounted for $6.9-27.3 \%$ of the cases, while pancolitis accounted for $10-45 \%$ of the cases. The proportion of patients with pancolitis was notably higher among patients from Kuwait, Lebanon, and Saudi Arabia. The majority of patients had mild/moderate severity of the disease. The protocol of IBD diagnosis was consistent across the included studies and composed mainly of endoscopy and biopsy. The extent of colon involvement was variable across the included studies.

\section{Treatment and Disease Outcomes}

The included studies reported similar treatment patterns, with the majority of patients receiving aminosalicylates or corticosteroids (alone or in combination) (Table 5). For example, a study from Saudi Arabia reported that 85.2\% of the patients were responsive to corticosteroids, while 7\% were corticosteroid-dependent, and $6.2 \%$ did not respond to corticosteroid treatment. Immunomodulators were used the least, and in all studies, few patients received anti-TNFa drugs. Hospitalization rates were reported for 3 studies and were generally considered to be high (Kuwait: $44.5 \%$; Saudi Arabia: 47\%; and Kuwait: 71\%).

Rates of UC-related surgery varied between 2.7 and 20\% among the included studies. Total colectomy rates in Egypt were $2.9 \%$. Among patients with UC in Bahrain, younger age correlated positively with the need for surgical intervention, anemia, and gastrointestinal complications. On the other hand, among Egyptian patients with UC, there was no correlation between extraintestinal manifestations and presence and UC severity. Among the included studies, 1

Epidemiology of IBD in Arab Countries

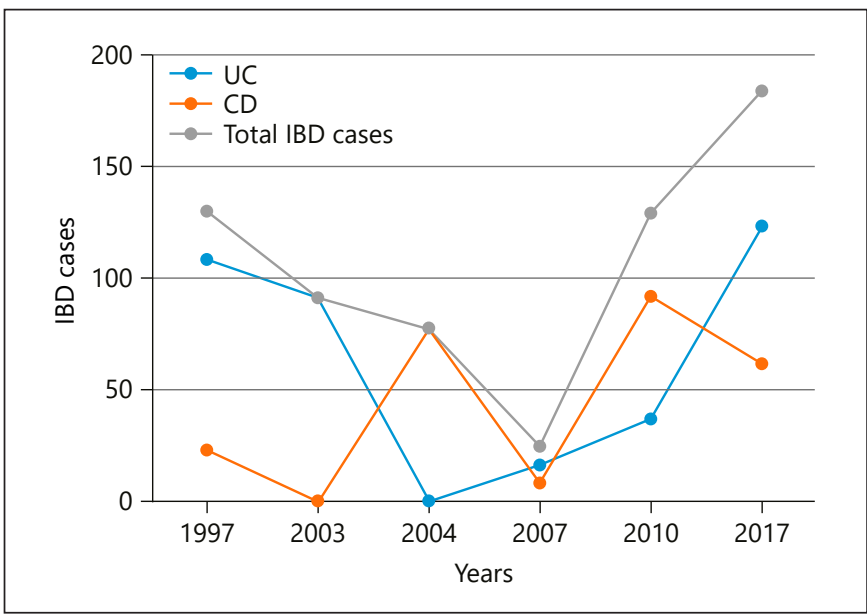

Fig. 2. Incidence and prevalence of IBD in the Arab world over the years. IBD, inflammatory bowel disease; CI, confidence interval.

case of colorectal cancer was reported in Egypt, 9 patients in Saudi Arabia, and 2 cases from Lebanon.

Only one included reported the impact of IBD on quality of life (QoL). Patients from Lebanon reported a moderately severe impact on QoL, as measured by the IBD QoL questionnaire.

\section{Discussion}

Although many recent reports highlighted a notable increase in the incidence of IBD in different parts of the Arab world, there is no published high-quality evidence 
Table 3. IBD characteristics among the included studies

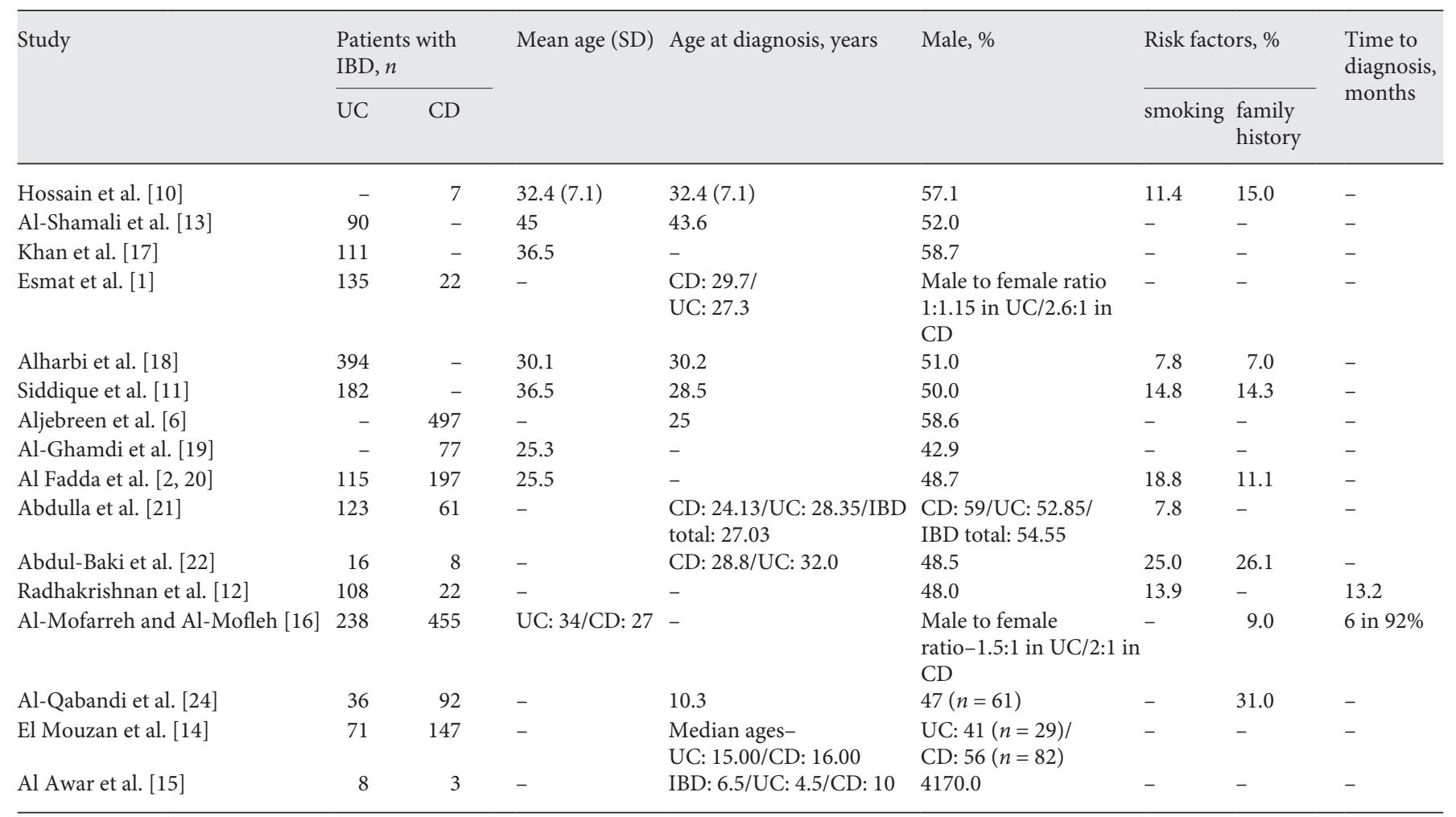

IBD, inflammatory bowel disease; CD, Crohn's disease; UC, ulcerative colitis; SD, standard deviation.

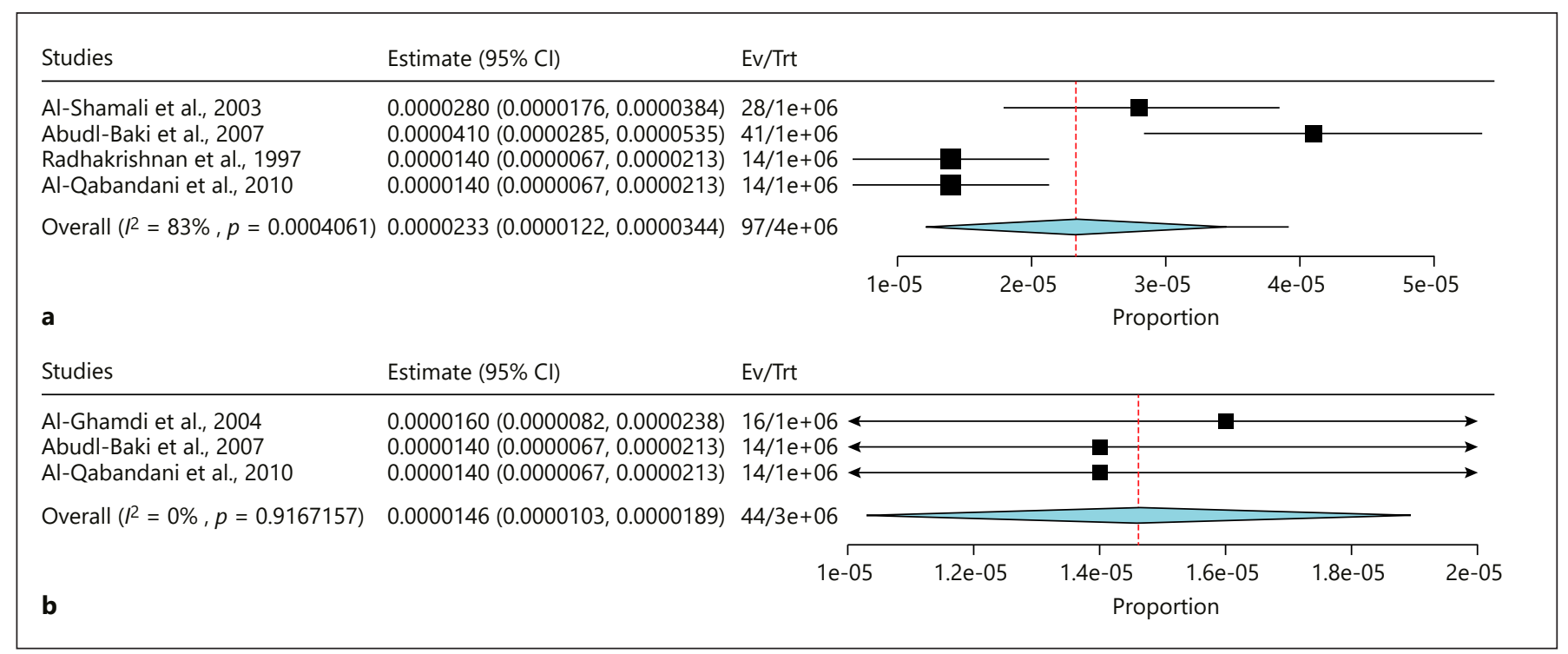

Fig. 3. Pooled estimates of the incidence of UC (a) and CD (b). IBD, inflammatory bowel disease; UC, ulcerative colitis; CD, Crohn's disease. 


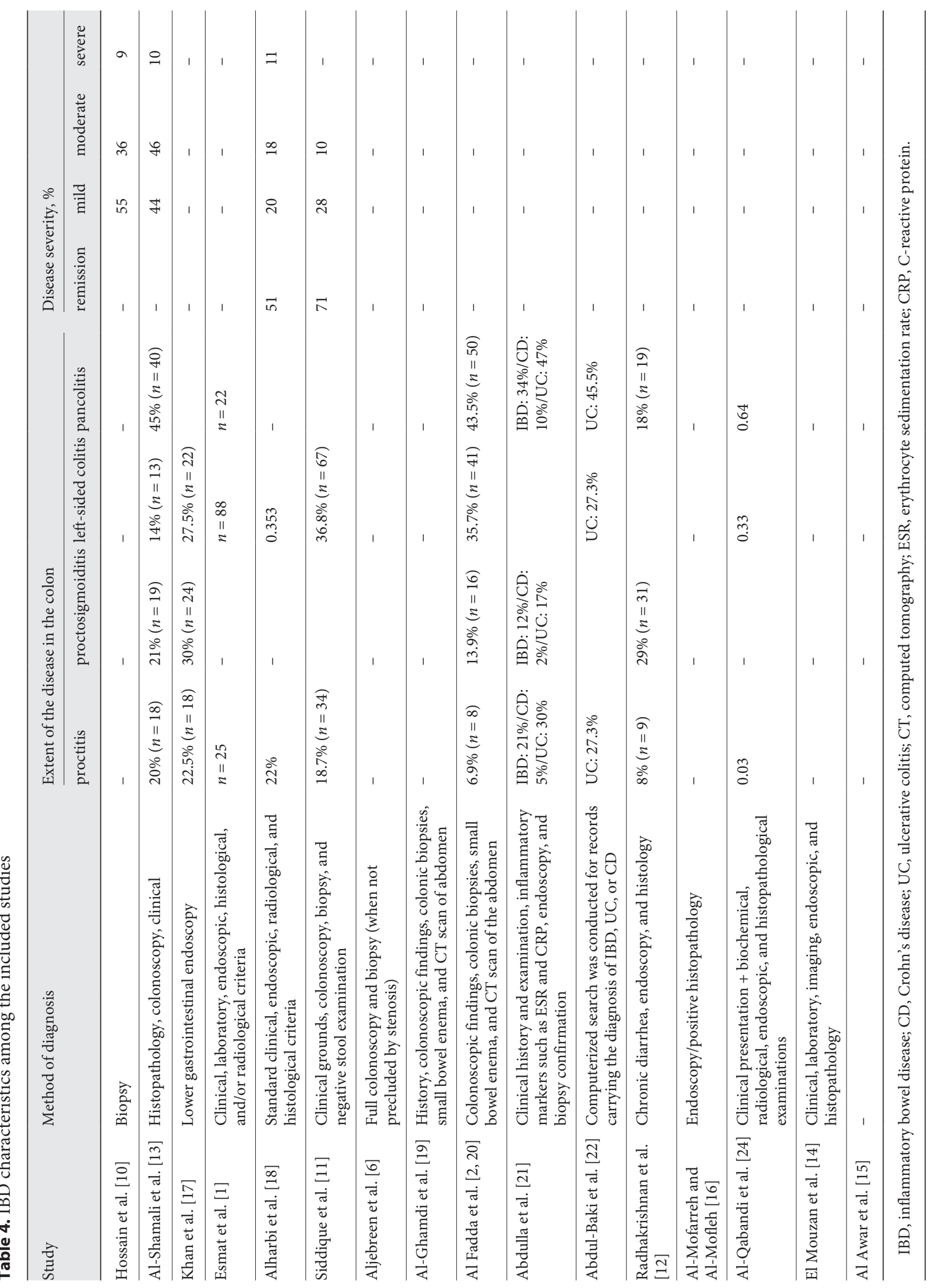


Table 5. Treatment characteristics among the included studies

\begin{tabular}{llllllr}
\hline Study & $\begin{array}{l}\text { Amino- } \\
\text { salicylates, } \%\end{array}$ & $\begin{array}{l}\text { Cortico- } \\
\text { steroids, \% }\end{array}$ & $\begin{array}{l}\text { Immuno- } \\
\text { modulators, \% }\end{array}$ & $\begin{array}{l}\text { Anti- } \\
\text { TNFa, \% }\end{array}$ & $\begin{array}{l}\text { Hospital- } \\
\text { ization, \% }\end{array}$ & $\begin{array}{l}\text { Surgery, } \\
\%\end{array}$ \\
\hline Al-Shamali et al. [13] & 93 & 60.0 & 68.0 & - & - & - \\
Alharbi et al. [18] & 100 & 73.6 & 37.9 & 4.9 & 44.5 & 3.8 \\
Siddique et al. [11] & 100 & 59.0 & 11.1 & - & 71.0 & - \\
Al Fadda et al. [2, 20] & 62 & 62.5 & 17.5 & 8.3 & - & 5.8 \\
Abdulla et al. [21] & 86 & 69.0 & 33.0 & 4.0 & 47.0 & 20.0 \\
\hline
\end{tabular}

TNFa, tumor necrosis factor alpha.

so far that attempted to examine the epidemiology of IBD in this part of the world. In the present systematic review, we found that the incidence of IBD is increasing exponentially in most of the Arab countries; our pooled estimates revealed that the incidence of $\mathrm{UC}$ and $\mathrm{CD}$ is approximating 2.33 and 1.46 per 100,000 persons per year, respectively. The highest incidence of IBD appears to be in $\mathrm{Ku}$ wait and KSA. On the other hand, the majority of IBD cases are diagnosed in young people, with a male preponderance. However, diagnostic modalities, the extent of the disease, and response to treatment appear to be similar to Western countries.

Prior to 1982, IBD was viewed as a rare condition in the ME, particularly in the KSA and Morocco [2]. This view was challenged in 1984 when a 6-year study on the epidemiology and incidence of IBD in the ME was conducted in Kuwait, reporting 91 patients with UC and 17 patients with $\mathrm{CD}[2,4]$. Further studies spanning the 1990s and 2000s in the KSA, Kuwait, Oman, and Egypt have since confirmed increasing annual rates of IBD [1, 2, 4, 12]. In Egypt, a 15-year case series study from 1995 to 2009 featuring 24,156 patients referred to a gastroenterology center found $135 \mathrm{UC}$ patients and $22 \mathrm{CD}$ patients, with a ratio of $6: 1$ for UC to CD etiologies [1]. Notably, more recent reports confirmed the significant rise in the incidence of IBD in Arab countries; for example, Al-Ghamdi et al. [19] retrieved the data of all confirmed cases with CD in a tertiary center in Riyadh City of KSA; it was found that the incidence of CD increased from 0.32 per 100,000 persons per year in the period of 1983-1993 to 1.66 per 100,000 persons per year in the period of 1994-2004 with a total mean annual incidence of 0.94 per 100,000 persons per year over these 20 years. In the present systematic review and meta-analysis, we confirmed that the upward trajectory of IBD incidence in the Arab world; we demonstrated that the incidence of $\mathrm{UC}$ and CD is approximating 2.33 and 1.46 per 100,000 persons per year, respectively. Many factors can contribute to this significant rise of IBD incidence, the increased "westernization" of a country is linked to subsequent increases in IBD incidence $[1,5-7,20]$ Another important factor to consider in the epidemiology of IBD is consanguinity [3], especially in the ME where consanguinity can be prevalent in some cultures $[3,7]$. The links between IBD and consanguinity are reinforced when considering the familial clusters of IBD, in addition to the 10-fold increase in IBD susceptibility seen in individuals with first-degree relative to IBD [3]. A study of 600 women from the KSA demonstrated a parental IBD consanguinity of $30 \%$ [3]. Nevertheless, current literature examining the influence of consanguinity on IBD prevalence in the ME have conflicting conclusions [3,7], which merits further studies in this area.

The gender preponderance (higher number of males) observed among the IBD patients from Arab countries contrasts with studies of the adult IBD population, where there are a slightly greater proportion of females with IBD in studies from Iran [25] and Sri Lanka [26], while studies in Japan [27], Korea [28], and other Asian countries [29] have shown a similar incidence in males and females.

Although the present systematic review is one of the few high-quality evidence about the IBD situation in the Arab world, there are some limitations that must be considered when assessing our findings. Our findings were based on data from 7 Arab countries only, with half of the report from KSA; thus, the generalizability of our findings in all Arab world countries is limited. In addition, only 1 study assessed the pediatric IBD, and thus, further studies are warranted to examine pediatric IBD in Arab countries. The small sample size and potential confounders may have either overestimated or underestimated the incidence of IBD as well. 


\section{Conclusion}

In conclusion, there is a growing incidence of IBD in the Arab world, while IBD patients from Arab countries may present with peculiar characteristics, compared to their counterparts in Europe. A deeper investigation into the variety of factors governing the incidence of IBD in the Arab world is warranted, especially when taking into account the increasing rate of IBD, alongside the peculiar socioeconomic variables in the local population.

\section{Conflict of Interest Statement}

All authors declared that they have no proprietary interests in the products described in the article.

\section{References}

1 Esmat S, El Nady M, Elfekki M, Elsherif Y, Naga $\mathrm{M}$. Epidemiological and clinical characteristics of inflammatory bowel diseases in Cairo, Egypt. World J Gastroenterol. 2014;20(3):814-21.

2 Al Fadda M, Peedikayil MC, Kagevi I, Al Kahtani K, Al Ben Mousa A, Al Ashgar HI, et al. Inflammatory bowel disease in Saudi Arabia: a hospital-based clinical study of 312 patients. Ann Saudi Med. 2012;32(3):276-82.

3 Mosli M, Alzahrani A, Showlag S, Alshehri A, Hejazi A, Alnefaie M, et al. A cross-sectional survey of multi-generation inflammatory bowel disease consanguinity and its relationship with disease onset. Saudi J Gastroenterol. 2017; 23(6):337-40.

4 Siddique I, Alazmi W, Al-Ali J, Al-Fadli A, Alateeqi N, Memon A, et al. Clinical epidemiology of Crohn's disease in Arabs based on the Montreal classification. Inflamm Bowel Dis. 2012; 18(9):1689-97.

5 Sharara AI, Al Awadhi S, Alharbi O, Al Dhahab H, Mounir M, Salese L, et al. Epidemiology, disease burden, and treatment challenges of ulcerative colitis in Africa and the Middle East. Expert Rev Gastroenterol Hepatol. 2018;12(9):883-97.

6 Aljebreen A, Alharbi O, Azzam N, Almalki A, Alswat K, Almadi M. Clinical epidemiology and phenotypic characteristics of Crohn's disease in the central region of Saudi Arabia. Saudi J Gastroenterol. 2014;20(3):162-9.

7 El Mouzan M, Al-Mofarreh M, Assiri A, Hamid Y, Saeed A. Consanguinity and inflammatory bowel diseases: is there a relation? J Pediatr Gastroenterol Nutr. 2013;56(2):182-5.

8 Stroup DF, Berlin JA, Morton SC, Olkin I, Williamson GD, Rennie D, et al. Meta-analysis of observational studies in epidemiology: a proposal for reporting. Meta-analysis of Observational Studies in Epidemiology (MOOSE) group. JAMA. 2000;283(15):2008-12.

9 Higgins JP, Green S. Cochrane handbook for systematic reviews of interventions: cochrane book series; 2008. vol. Version 5.

\section{Funding Source}

This work was supported by a financial grant from Gilead Sciences, Inc. as part of the company's support for Medical research in Saudi Arabia.

\section{Author Contributions}

All authors contributed equally in interpreting the results, editing, and finally approving the manuscript prior to submission.
10 Hossain J, Al-Mofleh IA, Laajam MA, AlRashed RS, Al-Faleh FZ. Crohn's disease in Arabs. Ann Saudi Med. 1991;11(1):40-6.

11 Siddique I, Alazmi W, Al-Ali J, Longenecker JC, Al-Fadli A, Hasan F, et al. Demography and clinical course of ulcerative colitis in Arabs: a study based on the Montreal classification. Scand J Gastroenterol. 2014;49(12):1432-40.

12 Radhakrishnan S, Zubaidi G, Daniel M, Sachdev GK, Mohan AN. Ulcerative colitis in Oman: a prospective study of the incidence and disease pattern from 1987 to 1994. Digestion. 1997;58(3):266-70.

13 Al-Shamali MA, Kalaoui M, Patty I, Hasan F, Khajah A, Al-Nakib B. Ulcerative colitis in Kuwait: a review of 90 cases. Digestion. 2003;67: 218-24.

14 El Mouzan MI, Al Mofarreh MA, Assiri AM, Hamid YH. Presenting features of childhoodonset inflammatory. 2012;33:423-8.

15 Al Awar B, Almurbati B. P1188 inflammatory bowel disease in children in United Arab Emirates. J Pediatr Gastroenterol Nutr. 2004; 39(Suppl 1):S508.

16 Al-Mofarreh M, Al-Mofleh I. Emerging inflammatory bowel disease in saudi outpatients: a report of 693 cases. Saudi J Gastroenterol. 2013;19:16-22.

17 Khan HA, Mahrous AS, Fachartz FI, Khawaja FI. Ulcerative colitis amongst the Saudis: sixyear experience from Al-Madinah region. Saudi J Gastroenterol. 1996;2(2):69-73.

18 Alharbi OR, Azzam NA, Almalki AS, Almadi MA, Alswat KA, Sadaf N, et al. Clinical epidemiology of ulcerative colitis in Arabs based on the Montréal classification. World J Gastroenterol. 2014;20(46):17525-31.

19 Al-Ghamdi AS, Al-Mofleh IA, Al-Rashed RS, Al-Amri SM, Aljebreen AM, Isnani AC, et al. Epidemiology and outcome of Crohn's disease in a teaching hospital in Riyadh. World J Gastroenterol. 2004;10(9):1341-4.
20 Al Fadda M, Peedikayil MC, Kagevi I, Al Kahtani K, Al Ben Mousa A, Al Ashgar HI, et al. Inflammatory bowel disease in Saudi Arabia: a hospital-based clinical study of 312 patients. Ann Saudi Med. 2012;32:276-82.

21 Abdulla M, Al Saeed M, Fardan RH, Alalwan HF, Ali Almosawi ZS, Almahroos AF, et al. Inflammatory bowel disease in Bahrain: singlecenter experience. Clin Exp Gastroenterol. 2017;10:133-45.

22 Abdul-Baki H, ElHajj I, El-Zahabi LM, Azar C, Aoun E, Zantout H, et al. Clinical epidemiology of inflammatory bowel disease in Lebanon. Inflamm Bowel Dis. 2007;13(4):475-80.

23 Larkin MA. Ulcerative colitis in children. South Med J. 1961;54:880-6.

24 Al-Qabandi WA, Buhamrah EK, Hamadi KA, Al-Osaimi SA, Al-Ruwayeh AA, Madda J. Inflammatory bowel disease in children, an evolving problem in Kuwait. Saudi J Gastroenterol. 2011 Sep-Oct;17(5):323-7.

25 Safarpour AR, Hosseini SV, Mehrabani D. Epidemiology of inflammatory bowel diseases in Iran and Asia: a mini review. Iran J Med Sci. 2013;38:140-9.

26 Subasinghe D, Nawarathna NM, Samarasekera DN. Disease characteristics of inflammatory bowel disease (IBD): findings from a tertiary care centre in South Asia. J Gastrointest Surg. 2011;15(9):1562-7.

27 Yoshida Y, Murata Y. Inflammatory bowel disease in Japan: studies of epidemiology and etiopathogenesis. Med Clin North Am. 1990;74.

28 Yang SK, Hong WS, Min YI, Kim HY, Yoo JY, Rhee PL, et al. Incidence and prevalence of ulcerative colitis in the Songpa-Kangdong district, Seoul, Korea, 1986-1997. J Gastroenterol Hepatol. 2000;15(9):1037-42.

29 Ng SC, Tang W, Ching JY, Wong M, Chow CM, Hui AJ, et al. Incidence and phenotype of inflammatory bowel disease based on results from the Asia-pacific Crohn's and colitis epidemiology study. Gastroenterology. 2013;145(1):158-65.e2. 